\title{
Yale SCHOOL OF MEDICINE
}

\section{MEDICAL SCHOOL SURVEY QUESTIONS: EDUCATION IN LABORATORY MEDICINE}

The purpose of this survey is to fill an important "knowledge gap" that has been identified by working groups of the Centers for Disease Control and others, specifically, an understanding of the current state of medical student education in the United States in the area of Laboratory Medicine, that is, the acquisition of medical science knowledge gleaned from the clinical laboratories and its effective use in patient care (please see accompanying letter from the $\mathrm{CDC}$ ). All allopathic and osteopathic medical schools are being asked to complete this survey. The benefits of this project will include aggregate knowledge of how this education is commonly accomplished, with the long term goal of using such knowledge, combined with that of other ongoing investigations such as focus groups of practicing physicians and surveys of residency training, to improve medical practice in the United States as related to Laboratory Medicine. Information provided will be aggregated with the goal of presentation and publication - no individual institutions will be identified without prior written authorization. The results of the survey will be forwarded to the participating institutions once the data analysis is completed. No significant risks associated with completion of this survey have been identified. As described in the accompanying letters, there is no compensation given to faculty who assist in completion of the survey. The survey has been determined to be exempt from complete IRB review under Category 2 exemptions by the Human Investigation Committee of the Yale School of Medicine.

Please identify your medical school by name so that we can keep track of responses (medical schools will NOT be identified individually in any publications or presentations of the results of this survey without prior written authorization):

Please identify the names of the individuals completing this survey and indicate their role at your institution, e.g., Deputy Dean for Education, Pathology Course Director, Faculty from Departments other than Pathology, Medical Student, etc:

\section{DEMOGRAPHICS}

Size of usual medical school entering class:

Is your institution: $\square$ State or Federal $\square$ Private 


\section{GENERAL ASPECTS OF DIAGNOSTIC LABORATORY MEDICINE}

Schools teach principles of clinical laboratory medicine in different parts of the curriculum. For this survey we define formal Laboratory Medicine teaching as activities whose primary goal is to instruct in or to evaluate knowledge of the correct way to order and interpret laboratory tests. For example, a required afternoon during a core Internal Medicine clerkship spent in a laboratory reviewing consultative diagnostic patient care issues would fit this definition but attendance at Internal Medicine morning report would not. Similarly, a didactic workshop on interpretive issues (for example, applications of Bayes Theorem, understanding the significance of a reference range) would fit this definition but a broad lecture on heart failure that mentions BNP would not. Other examples that fit the definition might include a lecture on urinalysis in a renal disease module, a workshop on thyroid tests in an endocrine module, or labs in a core microbiology course (but not most lectures in the course). Some schools have several sessions in the first or second year teaching about test characteristics (sensitivity, specificity, positive and negative predictive value, likelihood ratios, etc.), and these would fit the criteria. Note that this survey applies to laboratory medicine and not to anatomic or surgical pathology instruction nor to histopathology. Thus, an elective in surgical pathology would not fit the definition but an elective either solely in one or more clinical laboratories or an elective that combines the clinical laboratories with surgical pathology experience would fit the definition.

\section{QUESTIONS ABOUT YOUR DIAGNOSTIC LABORATORY MEDICINE TEACHING}

Please note that this first set of questions apply to diagnostic laboratory test instruction and do NOT include Transfusion Medicine, which will be asked about separately below.

1. Please indicate whether your medical students receive or may elect to receive Laboratory Medicine instruction in the pre-clinical and/or clinical portions of the curriculum and indicate for each part of the curriculum whether it is required or elective. If both a required activity and an elective activity are available in the same year, please check both for that year. If possible, please also indicate which years of a 4 year curriculum have either or both required/elective Laboratory Medicine instruction.

Select all that apply $\rightarrow$
Pre-Clinical Curriculum
Clinical Curriculum
Year 1
Year 2
Year 3
Year 4


2. Please estimate the number of hours of instruction each student receives in your REQUIRED Laboratory Medicine curriculum for each school year. (Hours = hours of instruction per student. For example, a one hour lecture to students or a group of 10 workshops all run simultaneously for one hour per student both equal one hour of student instruction)

\begin{tabular}{|c|c|c|c|c|}
\hline REQUIRED Laboratory Medicine hours per student $\rightarrow$ & Year 1 & Year 2 & Year 3 & Year 4 \\
\hline \multicolumn{5}{|l|}{ Lectures } \\
\hline \multicolumn{5}{|l|}{ Lab Time } \\
\hline \multicolumn{5}{|l|}{$\begin{array}{l}\text { Small Group Learning (Workshops/Problem-based } \\
\text { learning) }\end{array}$} \\
\hline \multicolumn{5}{|l|}{$\begin{array}{l}\text { Clinical teaching (e.g., a day with the laboratory } \\
\text { pathologists during a clinical clerkship) }\end{array}$} \\
\hline \multicolumn{5}{|l|}{$\begin{array}{l}\text { Electronic Teaching (on-line, not already counted in the } \\
\text { categories above) }\end{array}$} \\
\hline Other (please explain below) & & & & \\
\hline
\end{tabular}

3. Please indicate what disciplines and individuals are involved in your REQUIRED Laboratory Medicine curriculum. Please check the appropriate box for "Leaders" (principle role in organizing, scheduling, determining content), "Participants" or "Neither".

Select all that apply $\rightarrow$
Family Medicine physicians
Internal Medicine physicians
Laboratory Medicine/Pathology Physicians
PhD Laboratorians
Pathology Residents/Fellows
Medical Technologists
Other (please specify below):

4. In the pre-clinical portion of your school's curriculum, does your school have (select one):

A separate, distinct Laboratory Medicine course?

Integration of Laboratory Medicine teaching into another course or courses?

5. Does your school periodically have a formal review of the overall laboratory medicine curriculum by a Laboratory Medicine / Pathology physician? Y Yes $\square$ No 
6. Does your school periodically have a formal review of the overall laboratory medicine curriculum by a committee whose task is to evaluate the adequacy of the curriculum in this area? $\square$ Yes $\square$ No

7. Is competency in Clinical Laboratory Medicine formally evaluated as a distinct curriculum component?

$$
\square \text { Yes } \square \text { No }
$$

8. Please select the ELECTIVE activities that your school offers (select all that apply):

A A general internship 'survival course' that includes formal instruction in Laboratory Medicine (both diagnostic and Transfusion) among many components?

- A specialized internship 'survival course' dedicated almost exclusively to Laboratory Medicine or to Laboratory Medicine, Diagnostic Imaging and other diagnostic modalities?

A combined Pathology Elective that includes Laboratory Medicine aspects?

A dedicated Laboratory Medicine elective separate from a Surgical Pathology/Autopsy elective?

$\square$ Other (please describe)

9. Some medical centers have a formal Laboratory Medicine Consult Service. This type of service, staffed by attending clinical pathologists, responds to consult calls regarding laboratory test interpretation, best strategies for test ordering, toxicology interpretation questions and the like and provides verbal and/or written consultative reports. The service may be called Pathology Consult Service, Clinical Pathology Consult Service or another name. However, this Service is distinct from surgical pathology, cytopathology and Transfusion Medicine.

a) Do one or more of your major teaching hospitals have a Pathology and/or Laboratory Medicine Diagnostic Consult Service that provides verbal and/or written consultations as outlined above?
○ Yes
$\square$ No

b) If yes, does the service provide written, or just verbal, consultations (select one)?

$\square$ Written only $\square$ Verbal only $\square$ Both

c) If such a Service or Services exist at your teaching hospital(s), which of the following areas are covered:

\begin{tabular}{|l|l|l|}
\hline Coagulation & $\square$ Yes & $\square$ No \\
\hline Other hematology & $\square$ Yes & $\square$ No \\
\hline Toxicology and/or therapeutic drug monitoring & $\square$ Yes & $\square$ No \\
\hline Microbiology / virology & $\square$ Yes & $\square$ No \\
\hline Endocrinology & $\square$ Yes & $\square$ No \\
\hline Genetic testing & $\square$ Yes & $\square$ No \\
\hline All aspects of laboratory services & $\square$ Yes & $\square$ No \\
\hline
\end{tabular}

d) If yes, about how many students take an elective with this Service per year?

e) Is your response to 9 d) $\square$ an estimate or $\square$ actual? 
10. A medical student curriculum in Laboratory Medicine has been proposed by the Academy of Clinical Laboratory Physicians and Scientists (ACLPS), as have curricula in subdisciplines of Laboratory Medicine, e.g., molecular diagnostics, transfusion medicine.

a) Are you aware of nationally published curricula in Laboratory Medicine, such as that proposed by ACLPS? $\square$ Yes $\square$ No

b) Do you utilize nationally published curricular guidelines in the formulation of your school's medical student curriculum?

口 Yes

$\square$ No

11. If a national standardized examination in clinical laboratory medicine designed for medical students were easily available, how likely is it that your school would use it?

$\square$ Very unlikely $\square$ Somewhat unlikely

$\square$ Somewhat Likely

Very likely

12. How likely would you be to use such a national standardized exam to:

\begin{tabular}{|c|c|c|c|c|}
\hline Select the best response for each question $\rightarrow$ & $\begin{array}{l}\text { Very } \\
\text { Unlikely }\end{array}$ & $\begin{array}{l}\text { Somewhat } \\
\text { Unlikely }\end{array}$ & $\begin{array}{l}\text { Somewhat } \\
\text { Likely }\end{array}$ & $\begin{array}{l}\text { Very } \\
\text { Likely }\end{array}$ \\
\hline \multicolumn{5}{|l|}{$\begin{array}{l}\text { Benchmark your institution by offering it to your students } \\
\text { on a voluntary, anonymous basis? }\end{array}$} \\
\hline \multicolumn{5}{|l|}{$\begin{array}{l}\text { Benchmark your institution by offering it to your students } \\
\text { on a required, but anonymous basis? }\end{array}$} \\
\hline \multicolumn{5}{|l|}{$\begin{array}{l}\text { Help evaluate your students and institution by offering it } \\
\text { to students on a voluntary, non-anonymous basis? }\end{array}$} \\
\hline $\begin{array}{l}\text { Help evaluate your students and institution by offering it } \\
\text { to students on a required, non-anonymous basis? }\end{array}$ & & & & \\
\hline
\end{tabular}




\section{QUESTIONS ABOUT YOUR TRANSFUSION MEDICINE TEACHING}

13. Please indicate whether your medical students receive or may elect to receive Transfusion Medicine instruction in the pre-clinical and/or clinical portions of the curriculum and indicate for each part of the curriculum whether it is required or elective. If both a required activity and an elective activity are available in the same year, please check both for that year. If possible, please also indicate which years of a 4 year curriculum have either or both required/elective Transfusion Medicine instruction.

Select all that apply $\rightarrow$
Pre-Clinical Curriculum

14. Please estimate the number of hours of instruction each student receives in your REQUIRED Transfusion Medicine curriculum for each school year. (Hours = hours of instruction per student. For example, a one hour lecture to students or a group of 10 workshops all run simultaneously for one hour per student both equal one hour of student instruction)

\begin{tabular}{|c|c|c|c|c|}
\hline REQUIRED Transfusion Medicine hours per student $\rightarrow$ & Year 1 & Year 2 & Year 3 & Year 4 \\
\hline \multicolumn{5}{|l|}{ Lectures } \\
\hline \multicolumn{5}{|l|}{ Lab Time } \\
\hline \multicolumn{5}{|l|}{$\begin{array}{l}\text { Small Group Learning (Workshops/Problem-based } \\
\text { learning) }\end{array}$} \\
\hline \multicolumn{5}{|l|}{$\begin{array}{l}\text { Clinical teaching (e.g., a day with the laboratory } \\
\text { pathologists during a clinical clerkship) }\end{array}$} \\
\hline \multicolumn{5}{|l|}{$\begin{array}{l}\text { Electronic Teaching (on-line, not already counted in the } \\
\text { categories above) }\end{array}$} \\
\hline Other (please explain) & & & & \\
\hline
\end{tabular}




\section{BARRIERS TO LABORATORY MEDICINE EDUCATION}

15. Educators have identified various barriers to educating medical students in the optimal use of the clinical laboratory. Choosing among the descriptors below, please rate the following as to whether or not you believe these are significant issues at your institution:

$\begin{aligned} & \text { Select the best response for each question } \rightarrow \\ & \text { Lack of sufficient qualified faculty to teach } \\ & \text { Laboratory Medicine } \\ & \text { Lack of adequate instructional materials } \\ & \text { (books, online resources, etc) in } \\ & \text { Laboratory Medicine } \\ & \text { Lack of standardization of laboratory test } \\ & \text { nomenclature } \\ & \text { Lack of published guidelines for optimal } \\ & \text { diagnostic algorithms in the laboratory } \\ & \text { evaluation of specific conditions } \\ & \text { Lack of knowledge of best laboratory practices } \\ & \text { by many attending physicians } \\ & \text { Lack of knowledge of best laboratory practices } \\ & \text { by interns and residents, who in turn } \\ & \text { therefore do not accurately instruct } \\ & \text { students on their service }\end{aligned}$
$\begin{aligned} & \text { Lack of medical student interest in } \\ & \text { understanding principles of laboratory } \\ & \text { medicine }\end{aligned}$
$\begin{aligned} & \text { Lack of sufficient time in the pre-clinical phase } \\ & \text { of the curriculum } \\ & \text { the curriculum }\end{aligned}$




\section{EXTENDED COMMENTS}

Please describe what you believe works well and what you believe does not work well in Laboratory Medicine instruction and where you believe there may be gaps in the education of medical students in this area (whether nationally or locally).

Please enclose copies of any curricular materials (syllabi, schedules, etc.) that you believe will help us understand how you teach clinical laboratory medicine at your medical school and teaching hospitals.

Thank you very much for your assistance. We will mail you a summary of the survey results in 2011. 